\title{
Aspectos qualitativos da carcaça e carne de novilhos superjovens da raça Devon, terminados em pastagem tropical, recebendo diferentes níveis de concentrado
}

\section{Qualitative aspects of the carcass and meat of young steers Devon finished in tropical pasture, receiving different levels of concentrate}

\author{
Luís Fernando Glasenapp de Menezes ${ }^{1}$; Luciane Rumpel Segabinazzi ${ }^{*}$; \\ Leandro da Silva Freitas ${ }^{3}$; João Restle ${ }^{4}$; Ivan Luiz Brondani ${ }^{5}$; \\ Alisson Marian Callegaro ${ }^{6}$; Guilherme Joner ${ }^{6}$; Dari Celestino Alves Filho
}

\section{Resumo}

O objetivo desse trabalho foi avaliar as características de carcaça e da carne de novilhos Devon terminados em pastagem tropical (associação de pastagem de milheto - Pennisetum americanum (L.) Leeke - e capim papuã - Bracharia plantaginea $)$ recebendo diferentes níveis de suplementação $(0 ; 0,5$ ou $1,0 \%$ do peso corporal. Os animais apresentaram peso médio inicial de $300 \mathrm{~kg}$ e 15 meses de idade, e foram abatidos com peso médio de $353,0 \mathrm{~kg}$. A suplementação com ração concentrada até o nível de $1,0 \%$ do peso vivo (PV) dos animais proporcionou carcaças com melhor qualidade (maior rendimento de carcaça quente e fria, e maior espessura de gordura subcutânea, que refletiu em menor quebra ao resfriamento); carcaças mais compactas (menos compridas, com melhor conformação e maior espessura do coxão) quando comparados aos não suplementados. Além disso, os animais alimentados somente com pastagem, apresentaram carcaças com menor percentual de dianteiro (37,6 vs 38,9 e 38,8\%), maior percentual de músculo (65,5 vs 59,6 e 59,5\%), que refletiu em maior relação tecidual músculo:osso e porção comestível: osso do que os suplementados. Quanto as qualidades sensoriais e organolépticas, constatou-se que a carne proveniente de animais suplementados com até $1,0 \%$ do peso vivo, apresentaram maiores perdas à cocção $(24,1 \%$ vs $18,0 \%)$ e exigiram maior força para o cisalhamento da fibra $(3,37$ vs $2,05 \mathrm{kgf} / \mathrm{cm}^{3}$ ) quando comparado a carne dos animais não suplementados. $\mathrm{O}$ aumento do nível de suplementação de $0,5 \%$ para $1,0 \%$ do PV melhorou a palatabilidade e reduziu a textura da carne.

Palavras-chave: Cortes comerciais, maciez, marmoreio, milheto, rendimento de carcaça

\begin{abstract}
The objective of this work was to evaluate the carcass and meat characteristics of young steers Devon, finished in tropical pasture (association of millet pasture - Pennisetum americanum (L.) Leeke and
\end{abstract}

\footnotetext{
${ }^{1}$ Zootecnista, Prof. Dr. do Dept ${ }^{\mathrm{o}}$ de Zootecnia Universidade Tecnológica Federal do Paraná, UTFPR, Dois Vizinhos, PR. E-mail: 1fgdm@hotmail.com

${ }^{2}$ Zootecnista, Dra , Pós-Doutoranda do Programa de Pós-Graduação, UTFPR, Dois Vizinhos, PR. E-mail: luzoot@hotmail.com

${ }^{3}$ Zootecnista, Prof. Dr. do Instituto Federal Farroupilha de Alegrete, RS. E-mail: freitaszoot@hotmail.com

${ }^{4}$ Eng $^{\text {o Agr }}{ }^{\text {o }}$ Prof. Dr. da Universidade Federal de Tocantins, UFT, Araguaína, TO. E-mail: jorestle@terra.com.br

${ }^{5}$ Zootecnista, Prof. Dr. da Universidade Federal de Santa Maria, UFSM, Santa Maria, RS. E-mail: brondani@pq.cnpq.br

${ }^{6}$ Zootecnistas, Discentes de Mestrado do Programa de Pós-Graduação, UFSM, Santa Maria, RS. E-mail: mcalisson@yahoo.com.br; jonerzootecnista@hotmail.com

${ }^{7}$ Eng $^{\circ}$ Agr ${ }^{\circ}$, Prof. Dr. da UFSM, Santa Maria, RS. E-mail: darialvesfilho@hotmail.com

* Autora para correspondência
} 
Alexander grass - Brachiaria plantaginea), receiving different levels of supplementation $(0 ; 0,5 \%$ or $1,0 \%$ of body weight). The animals had an average initial weight of $300 \mathrm{~kg}$ and 15 months of age, and were slaughtered at an average weight of $353.0 \mathrm{~kg}$. Supplementation with concentrate ration to the level of $1.0 \%$ of body weight (BW) of animal provided carcasses with better quality (higher hot and cold carcass, and greater fat thickness, which resulted in lower cooling loss); carcasses more compact (less long, with better conformation and thicker cushion) when compared to non-supplemented. Furthermore, animals fed only pasture, showed a lower percentage of carcasses forequarter (37.6 vs 38.9 e $38.8 \%$ ), with a higher percentage of muscle (65.5 vs 59.6 e $59.5 \%$ ), which resulted in greater relative muscle tissue: bone and edible portion: bone than those supplemented. As the sensory and organoleptic qualities, it was found that meat from animals supplemented with up to $1.0 \%$ of body weight, showed greater losses to cooking (24.1\% vs $18.0 \%$ ) and required greater force to shear the fiber (3.37 vs 2.05 (kgf/ $\mathrm{cm} 3$ ) compared to meat non-supplemented animals. However, the increased level of supplementation of $0.5 \%$ to $1.0 \%$ of $\mathrm{BW}$ improved palatability and reduced meat texture.

Key words: Commercial cuts, dressing percentage, marbling, millet, tenderness

\section{Introdução}

O Brasil está consolidado como um dos principais produtores de carne bovina do mundo, porém, o preço da carne brasileira ainda está abaixo daqueles praticados em países desenvolvidos, sendo que essa desvalorização deve-se ainda, em parte, à baixa qualidade das carcaças brasileiras. Essa qualidade pode ser alterada em função da idade de abate, grupo genético, pesos de abate, sistemas de produção, e particularmente, ao manejo nutricional adotado. Neste contexto, tendo em vista que aproximadamente $85 \%$ do rebanho brasileiro é mantido em sistema de pastejo, em forrageiras tropicais, torna-se pertinente a aplicação de um manejo nutricional mais eficiente para esse tipo de pastagem.

Menezes et al. (2010) relataram que animais terminados exclusivamente em pastagem tropical apresentam carcaça de menor qualidade em relação aos terminados em pastagem cultivada de inverno ou confinamento. Isso retrata a necessidade de técnicas que implicam em melhorias na eficiência de aproveitamento dos nutrientes disponíveis via pastagens, dentre elas, o uso de concentrado na dieta, uma vez que implicam na melhoria da qualidade da carcaça (VAZ et al., 2005; BARONI et al., 2010; REZENDE; RESTLE; FERNANDES, 2012). Porém, informações referente a qualidade da carcaça e carne de bovinos em pastagem, recebendo diferentes níveis de suplementação energética ainda são escassas e contraditórias e necessitam de mais estudos, principalmente no que se refere ao nível mais adequado, quando se trabalha com pastagens tropicais. Restle et al. (2001a) e Vaz et al. (2002) trabalhando com pastagem de inverno, não observaram efeito na qualidade de carcaça com o aumento do nível suplementação para vacas de descarte. Por outro lado, Santos et al. (2002), trabalhando com novilhos em pastagem de Brachiaria observaram maior peso de carcaça, espessura de gordura subcutânea e percentagem de gordura na carcaça em novilhos suplementados. Enquanto que, Osmari et al. (2008) observaram melhora na conformação da carcaça de vacas suplementadas ao nível de $0,5 \%$ do peso vivo, em campo nativo no sul do Brasil.

Com relação ao fator racial, o rebanho bovino de corte no sul do Brasil, ao contrário do restante do país, apresenta número expressivo de animais de raças européias britânicas e continentais definidas ou puras, principalmente as das raças Aberdeen Angus, Hereford e Devon (RESTLE; PACHECO; VAZ, 2003). Esta última, segundo Marshall (1994), está entre as raças que apresentam carne mais macia, tanto medidas pelo aparelho Warner Blatzler Shear como pelo painel de degustadores.

Diante desse contexto, este estudo objetivou 
avaliar o uso de diferentes níveis de suplementação energética em pastagem tropical sobre as características da carcaça e da carne de novilhos Devons superjovens.

\section{Material e Métodos}

O trabalho foi realizado na fazenda experimental pertencente ao Laboratório de Bovinocultura de Corte do Departamento de Zootecnia da Universidade Federal de Santa Maria, situada na Depressão Central do Rio Grande do Sul, em uma latitude de $95 \mathrm{~m}$, latitude de $29^{\circ} 43^{\prime}$ sul e longitude $53^{\circ} 42^{\prime}$.

Foram avaliadas as características de carcaça e da carne de novilhos terminados em pastagem cultivada de verão, composta de milheto (Pennisetum americanum) e capim papuã (Brachiara plantaginea), recebendo ou não suplementação energética ao nível equivalente a $0,5 \%$ ou $1,0 \%$ do peso vivo. Foram utilizados doze novilhos castrados da raça Devon com peso e idade média inicial de 300 $\mathrm{kg}$ e 13 meses. Os animais, provenientes de mesmo rebanho e mesmas condições de alimentação e manejo, antes do experimento, foram mantidos em pastagem cultivada de inverno.

Os animais foram mantidos em piquetes de aproximadamente 1 há, sendo utilizados dois piquetes por tratamento. A dieta era composta por pastagem de milheto (Pennisetum americanum) e papuã (Brachiaria plantaginea), e o suplemento, fornecido somente uma vez ao dia (14 horas), composto de farelo de trigo, calcário calcítico, cloreto de sódio e monensina sódica, com 13,9\% de PB e $71,4 \%$ de NDT.

O sistema de pastejo empregado foi o contínuo, com lotação variável, utilizando a técnica put and take descrita por Mott e Lucas (1952). Procurouse manter uma oferta de forragem de 10\% para todos os animais dos tratamentos, e para tal, foram realizadas avaliações a cada 14 dias, através da técnica da dupla amostragem. Juntamente as avaliações eram realizadas simulações de pastejo para determinação da composição bromatológica do material ingerido pelos animais. Os animais foram abatidos quando chegaram ao mesmo peso de abate $(350 \mathrm{~kg})$, que foi estipulado segundo o grau de acabamento da carcaça, e que, segundo a preferência dos frigoríficos deve estar com, no mínimo, $3 \mathrm{~mm}$ de espessura de gordura subcutânea. Os animais que receberam suplemento apresentaram ganho médio diário (GMD) de 0,580 $\mathrm{kg}$ e foram abatidos após 85 dias, enquanto que àqueles que se alimentaram somente de pastagem, apresentaram GMD de 0,370 kg e necessitaram 135 dias para chegar ao peso de abate.

Antes do embarque para o frigorífico, os animais foram submetidos a jejum de sólidos e líquidos de 12 horas, sendo posteriormente pesados, obtendo-se, dessa maneira, o peso de abate dos animais. O abate seguiu o fluxo normal do estabelecimento conforme o Regulamento de Inspeção Industrial e Sanitária de Produtos de Origem Animal (RIISPOA). As carcaças foram identificadas e pesadas antes e após serem resfriadas em câmara fria, por 24 horas, a $0{ }^{\circ} \mathrm{C}$, de modo a obter os pesos e rendimentos de carcaça quente e fria, bem como as perdas ao resfriamento. Após, as pesagens, avaliou-se a conformação e a maturidade fisiológica da carcaça, segundo a metodologia de Müller (1987).

A metade esquerda da carcaça foi separada nos cortes comerciais primários: dianteiro, costilhar (ponta de agulha) e serrote (traseiro especial), sendo estes pesados, para posterior cálculo de sua porcentagem em relação à carcaça inteira. $\mathrm{Na}$ meia-carcaça direita, foram mensurados, segundo Müller (1987), os comprimentos de carcaça, de perna e de braço, a espessura de coxão e o perímetro de braço. Entre a $12^{\text {a }}$ e a $13^{\text {a }}$ costelas, realizou-se um corte horizontal visando expor o músculo Longissimus dorsi, para obtenção da sua área, comumente conhecida por Área de Olho de Lombo (AOL). No mesmo local, foi medida 
a espessura de gordura subcutânea obtida pela média de três observações, e foram realizadas as avaliações subjetivas de marmoreio, coloração e textura da carne.

Para determinar as porcentagens de músculo, gordura e osso, seguiu-se a metodologia descrita por Hankins e Howe (1946), adaptada por Müller, Maxon e Palmer (1973), sendo que a porção do músculo Longissimus dorsi extraída dessas determinações foi identificada, embalada e imediatamente congelada para posterior determinação das características sensoriais.

Em laboratório, do músculo congelado foram cortadas duas fatias de $2,5 \mathrm{~cm}$ de espessura perpendicularmente ao comprimento do músculo, as quais foram utilizadas para avaliação das características sensoriais (fatia A), e perdas de líquido ao descongelamento, à cocção, bem como a resistência das fibras (fatia B). As características sensoriais da carne foram avaliadas segundo Müller (1987). Para o cálculo das perdas ao descongelamento e à cocção, foi realizada a pesagem da fatia $\mathrm{B}$, congelada, descongelada e após o cozimento, que aconteceu até que a temperatura interna da fatia atingisse $70^{\circ} \mathrm{C}$. A pesagem após o cozimento foi realizada após a amostra atingir a temperatura ambiente. Em seguida, foi avaliada a força de resistência das fibras com o auxílio do aparelho Warner-Bratzler Shear, para tal, foram extraídas seis amostras perpendiculares à fibra, de 1,2 $\mathrm{cm}^{2}$ de área cada.

$\mathrm{O}$ delineamento experimental utilizado foi o inteiramente casualizado, com três tratamentos e quatro repetições. Os dados foram submetidos a análise de variância e as médias comparadas pelo teste ' $t$ ', ao nível de 5 e $10 \%$ de probabilidade com auxílio do programa estatístico (SAS, 2002). Além disso, foi realizada análise de regressão linear. O mesmo programa realizou o estudo de correlação entre as variáveis dependentes através do cálculo dos coeficientes de correlação de Pearson. A normalidade dos dados foi testada pelo teste Shapiro-Wilk.

\section{Resultados e Discussão}

Tendo em vista que o peso de abate foi predeterminado, estes não foram influenciados pelos níveis de concentrado na dieta (Tabela 1). O peso de carcaça ficou acima de $180 \mathrm{~kg}$, o que é aceitável pelos frigoríficos, uma vez que são carcaças de animais abatidos ainda muito jovens. Nesse caso, embora esses animais apresentem carcaças mais leves, se as carcaças estiverem com acabamento adequado, a carne tende a ser de melhor qualidade. 
Tabela 1. Médias, erros-padrão e coeficiente de variação (CV) das características de carcaça de novilhos da raça Devon, recebendo ou não diferentes níveis de concentrado durante a terminação em pastagem tropical de milheto.

\begin{tabular}{lllll}
\hline & \multicolumn{3}{c}{ Níveis de suplementação, \% do PV } & CV, \% \\
\cline { 2 - 4 } & \multicolumn{1}{c}{0} & 0,5 & 1,0 & 3,63 \\
Peso de abate, kg & $355,0 \pm 6,4$ & $354,0 \pm 7,4$ & $350,5 \pm 6,4$ & 4,42 \\
Peso de carcaça quente, kg & $191,4 \pm 4,3$ & $192,2 \pm 5,0$ & $198,7 \pm 4,3$ & 2,70 \\
RCQ, \% ${ }^{(1)}$ & $53,9 \pm 0,7^{\mathrm{b}}$ & $54,3 \pm 0,9^{\mathrm{b}}$ & $56,7 \pm 0,7^{\mathrm{a}}$ & 4,37 \\
Peso de carcaça fria, kg & $186,0 \pm 4,1$ & $188,1 \pm 4,8$ & $194,6 \pm 4,1$ & 2,67 \\
RCF, \% & $52,4 \pm 0,7^{\mathrm{b}}$ & $53,1 \pm 0,8^{\mathrm{b}}$ & $55,5 \pm 0,7^{\mathrm{a}}$ & 5,57 \\
Quebra ao resfriamento, \% & $2,85 \pm 0,07^{\mathrm{a}}$ & $2,14 \pm 0,08^{\mathrm{b}}$ & $2,08 \pm 0,07^{\mathrm{b}}$ & 34,67 \\
Espessura de gordura, mm & $2,75 \pm 0,7^{\mathrm{B}}$ & $4,77 \pm 0,8^{\mathrm{A}}$ & $4,58 \pm 0,7^{\mathrm{A}}$ & 7,81 \\
Conformação, pontos ${ }^{(2)}$ & $7,75 \pm 0,3^{\mathrm{b}}$ & $8,33 \pm 0,4^{\mathrm{ab}}$ & $9,00 \pm 0,3^{\mathrm{a}}$ & 10,66 \\
AOL, cm ${ }^{2}(1)$ & $56,8 \pm 2,9$ & $49,6 \pm 3,3$ & $53,5 \pm 2,9$ & 4,02 \\
Espessura de coxão, cm & $22,8 \pm 0,5^{\mathrm{b}}$ & $26,4 \pm 0,6^{\mathrm{a}}$ & $26,9 \pm 0,5^{\mathrm{a}}$ & 4,47 \\
Perímetro de braço, cm & $32,3 \pm 0,7$ & $31,3 \pm 0,8$ & $31,0 \pm 0,7$ & 1,81 \\
Comprimento de carcaça,cm & $118,9 \pm 1,0^{\mathrm{a}}$ & $114,7 \pm 1,2^{\mathrm{b}}$ & $115,0 \pm 1,1^{\mathrm{b}}$ & 5,62 \\
Comprimento de perna, cm & $64,4 \pm 1,7^{\mathrm{a}}$ & $57,7 \pm 2,0^{\mathrm{b}}$ & $62,7 \pm 1,7^{\mathrm{ab}}$ & 1,19 \\
Comprimento de braço, cm & $37,4 \pm 0,6$ & $37,0 \pm 0,7$ & $35,9 \pm 0,6$ & \\
\hline
\end{tabular}

a,b letras minúsculas diferentes, na linha, diferem $(\mathrm{P}<0,05)$ entre si pelo teste ' $\mathrm{t}$ '

$\mathrm{A}, \mathrm{B}$ letras maiúscula diferentes, na linha, diferem $(\mathrm{P}<0,10)$ entre si pelo teste ' $\mathrm{t}$ '

(1) RCQ - rendimento de carcaça quente; RCF - rendimento de carcaça fria; AOL - Área de do músculo Longissimus dorsi

(2) Escala de 1 a 18 pontos, sendo $7=$ regular menos; 8=regular; 9=regular mais.

Fonte: Elaboração dos autores.

Os rendimentos de carcaça quente e fria foram influenciados pelo nível de suplementação, sendo que os maiores rendimentos foram para aquelas carcaças provenientes de animais que receberam concentrado ao nível de 1,0 \% do PV. A principal explicação para a variação no rendimento de carcaça em animais de mesma idade, grupo genético e peso de abate é a dieta imposta a eles. Dietas com maior digestibilidade tendem a apresentar menor conteúdo gastrintestinal (RIBEIRO et al., 2001). No presente estudo o conteúdo do trato gastrintestinal foi influenciado de forma linear $(\mathrm{Y}=53,16-14,93 * \mathrm{NS}$; $\left.\mathrm{P}=0,0038 ; \mathrm{R}^{2}=0,62\right)$ pelo nível de concentrado $(54,35 ; 42,53$ e $39,43 \mathrm{~kg}$, para os níveis $0 ; 0,5$ e $1,0 \%$, respectivamente), apresentando correlação negativa com o rendimento de carcaça quente $(\mathrm{r}=$ $0,57 ; \mathrm{P}=0,0649)$ e fria $(\mathrm{r}=-0,63 ; \mathrm{P}=0,0373)$.

Vários estudos em confinamento já foram conduzidos com o intuito de determinar a melhor relação volumoso: concentrado, porém com resultados contraditórios (GESUALDI JÚNIOR et al., 2000; SILVA et al., 2002; MISSIO et al., 2010). Em pastejo, Restle et al. (2001a, 2001b) não encontraram diferença no rendimento de carcaça de vacas de descarte recebendo níveis crescentes de suplementação. Estes pesquisadores justificaram a ausência de diferença no rendimento de carcaça pela alta velocidade de passagem da pastagem cultivada de inverno (aveia + azevém) pelo trato digestivo, uma vez que o conteúdo do trato gastrintestinal é um dos principais responsáveis pela variação no rendimento de carcaça.

Além do conteúdo do trato gastrintestinal, Ribeiro et al. (2001), atribuíram à menor espessura de gordura na carcaça de animais alimentados com menores níveis de concentrado como um fator que infere menores rendimentos, uma vez que a deficiência de tecido adiposo pode levar ao ressecamento causado pelo resfriamento. Porém, apesar da espessura de gordura ter sido maior em 
animais que receberam concentrado na dieta (Tabela 1), esta não apresentou relação com os rendimentos de carcaça.

A perda de peso de carcaça durante o resfriamento foi menor nas carcaças dos novilhos que não receberam suplemento, em comparação aos que receberam suplementação. Quando analisada por meio da regressão, a quebra foi influenciada linearmente com o aumento no nível de concentrado na dieta $\left(\mathrm{Y}=2,76-0,77 * \mathrm{NS} ; \mathrm{P}=0,0004 ; \mathrm{R}^{2}=0,77\right)$. A quebra ao resfriamento reflete a perda de peso que a carcaça sofre durante o processo de resfriamento nas primeiras 24 horas após o abate e segundo Müller (1987), a espessura de gordura que recobre a carcaça reduz as perdas por desidratação durante o resfriamento, uma vez que esta funciona como isolante térmico. A quebra ao resfriamento se correlacionou negativamente com a espessura de gordura subcutânea $(\mathrm{r}=-0,76 ; \mathrm{P}=0,0061)$ e com a conformação da carcaça $(r=-0,65 ; \mathrm{P}=0,0290)$.

A espessura de gordura foi influenciada pela inclusão do concentrado na dieta (Tabela 1). A deposição de gordura nos animais depende do grupo genético, do peso vivo do animal, da intensidade do ganho de peso diário, da maturidade e da densidade energética da dieta (NRC, 1996). Destes fatores a densidade energética e o ganho de peso médio diário (GMD) foram diferentes entre os tratamentos. Observa-se que o menor grau de cobertura de gordura na carcaça foi nos animais que não receberam suplementação. Além disso, a espessura de gordura subcutânea acompanhou o GMD dos animais nos tratamentos $(0,370 ; 0,635$ e $0,588 \mathrm{~kg}$, para os níveis $0 ; 0,5$ e 1,0\% do peso vivo, respectivamente). Esse comportamento deve-se ao princípio de que uma vez atendidas as exigências de mantença, crescimento dos órgãos e dos tecidos, o excedente de energia consumida é depositado sob a forma de gordura.

Observa-se que os animais que não receberam suplementação apresentaram carcaças com gordura subcutânea abaixo de $3 \mathrm{~mm}$ de espessura, enquanto que as carcaças dos animais suplementados apresentaram gordura de cobertura dentro do limite desejado. Além de prejudicar a qualidade da carcaça, como o escurecimento e aumento na quebra ao resfriamento da carcaça (Tabela 1), o baixo grau de acabamento também prejudica a rentabilidade do produtor, uma vez que frigoríficos desvalorizam carcaças com esta característica. Estes resultados apontam que para a terminação de animais em pastagem de milheto sem suplementação há necessidade de maior peso de abate para melhoria na qualidade da carcaça, principalmente na questão de deposição mínima de gordura. Utilizando níveis crescentes de suplementação em pastagem de azevém+triticale, Restle et al. (2001a) observaram que o incremento no nível de suplementação aumentou o grau de acabamento da carcaça de vacas de descarte, observando que para as carcaças apresentarem o mínimo exigido $(3 \mathrm{~mm})$ pelos frigoríficos foi necessário suplementação de $0,55 \%$ do PV.

Das características que expressam a musculosidade da carcaça, a área do músculo Longissimus dorsi (AOL) e o perímetro e o comprimento de braço não foram afetados pela suplementação (Tabela 1). Restle et al. (2001a), também não observaram efeito da suplementação nas características que medem o desenvolvimento da carcaça de vacas de descarte terminadas em pastagem cultivadas de inverno.

Diferente do observado por Restle et al. (2001a, 2001b) e Missio et al. (2010), o aumento do nível de concentrado na dieta proporcionou aumento no grau de conformação (CONF) e da espessura de coxão (ESPCOX) da carcaça, tanto pela análise de variância como pela análise de regressão $\left(\mathrm{CONF}=7,738+1,250 * \mathrm{NS} ; \mathrm{P}=0,0186 ; \mathrm{R}^{2}=0,48\right.$ e $\left.\mathrm{ESPCOX}=23,192+4,215^{*} \mathrm{NS} ; \mathrm{P}=0,0012 ; \mathrm{R}^{2}=0,71\right)$. Este resultado concorda em parte com Ribeiro et al. (2001) que afirmaram que a energia adicional fornecida via concentrado é utilizada para deposição muscular. Segundo Müler (1987), carcaças com melhor conformação tendem a apresentar menor 
proporção de osso e maior porção comestível, o que não ocorreu no presente estudo.

Diferente do ocorrido com a conformação e a espessura de coxão, os comprimentos de carcaça e de perna foram influenciados negativamente pela inclusão de concentrado na deita. Pela análise de regressão linear, apenas para o comprimento de carcaça houve efeito significativo ( $\mathrm{Y}=118,256$ $\left.3,875^{*} \mathrm{NS} ; \mathrm{P}=0,0394 ; \mathrm{R}^{2}=0,39\right)$. Essa diminuição no comprimento de carcaça com o aumento no nível de concentrado na dieta se deve aos animais ficarem mais compactos (GESUALDI JÚNIOR et al., 2000). O decréscimo na medida de comprimento de perna com o aumento no nível de suplementação foi uma resposta inesperada, causada provavelmente, por diferenças existentes entre os animais na formação dos lotes no início do experimento, já que os lotes foram formados buscando equilibrar o peso e estado corporal dos animais, não sendo incluídos dados de altura.
Não houve variação no peso e na percentagem do costilhar (ponta de agulha) e no traseiro (serrote) com o aumento no nível de suplementação (Tabela 2). Jardim, Guarenti e Osório (1988) verificaram que $58 \%$ da variação total no peso do dianteiro, $50 \%$ da variação total no peso do costilhar e $92 \%$ da variação total no peso do traseiro se devem à variação no peso da carcaça, não verificando influência significativa do peso de carcaça sobre as porcentagens dos cortes comerciais.

$\mathrm{O}$ peso e percentagem do dianteiro foram influenciados pelos diferentes níveis de suplementação alimentar em pastagem, no entanto, o peso foi similar para aqueles que receberam $0,5 \%$ de concentrado e os alimentados somente com pastagem. No entanto, segunda a análise de regressão, verificou-se aumento linear no peso (Dianteiro, $\left.\mathrm{kg}=70,060+5,550 * \mathrm{NS} ; \quad \mathrm{P}=0,0347 ; \quad \mathrm{R}^{2}=0,41\right) \quad \mathrm{e}$ percentagem (Dianteiro, $\%=37,803+1,184 * \mathrm{NS}$; $\left.\mathrm{P}=0,0225 ; \mathrm{R}^{2}=0,46\right)$ de dianteiro com o aumento no nível de suplementação.

Tabela 2. Médias e erros-padrão e coeficiente de variação (CV) do peso e participação dos cortes primários e composição física da carcaça de novilhos da raça Devon, mantidos em pastagem de milheto, de acordo com o nível de suplementação.

\begin{tabular}{lcccc}
\hline & \multicolumn{3}{c}{ Níveis de suplementação, \% do peso vivo CV, \% } \\
\cline { 2 - 4 } & 0 & 0,5 & 1,0 & \\
\hline Costilhar, kg & $23,5 \pm 0,9$ & $23,3 \pm 1,1$ & $24,9 \pm 0,9$ & 7,66 \\
Costilhar, \% & $12,6 \pm 0,5$ & $12,4 \pm 0,5$ & $12,8 \pm 0,5$ & 7,15 \\
Traseiro, kg & $89,7 \pm 2,4$ & $89,9 \pm 2,8$ & $93,8 \pm 2,4$ & 5,32 \\
Traseiro, \% & $48,3 \pm 0,9$ & $47,8 \pm 1,0$ & $48,2 \pm 0,9$ & 3,55 \\
Dianteiro, kg & $69,9 \pm 1,7^{\mathrm{b}}$ & $73,1 \pm 1,9^{\mathrm{ab}}$ & $75,5 \pm 1,7^{\mathrm{a}}$ & 4,56 \\
Dianteiro, \% & $37,6 \pm 0,3^{\mathrm{b}}$ & $38,9 \pm 0,3^{\mathrm{a}}$ & $38,8 \pm 0,3^{\mathrm{a}}$ & 1,41 \\
Músculo, kg & $121,6 \pm 3,0^{\mathrm{b}}$ & $112,2 \pm 3,5^{\mathrm{b}}$ & $115,5 \pm 3,0^{\mathrm{ab}}$ & 5,16 \\
Músculo, \% & $65,5 \pm 1,5^{\mathrm{a}}$ & $59,6 \pm 1,7^{\mathrm{b}}$ & $59,5 \pm 1,5^{\mathrm{b}}$ & 4,71 \\
Gordura, kg & $36,3 \pm 3,3^{\mathrm{b}}$ & $43,3 \pm 3,8^{\mathrm{ab}}$ & $45,1 \pm 3,3^{\mathrm{a}}$ & 15,94 \\
Gordura, \% & $19,4 \pm 1,5$ & $23,1 \pm 1,8$ & $23,1 \pm 1,5$ & 13,96 \\
Ossos, kg & $28,6 \pm 0,9^{\mathrm{b}}$ & $31,8 \pm 1,1^{\mathrm{a}}$ & $33,1 \pm 1,0^{\mathrm{a}}$ & 5,97 \\
Ossos, \% & $15,4 \pm 0,5^{\mathrm{b}}$ & $16,9 \pm 0,5^{\mathrm{a}}$ & $17,0 \pm 0,5^{\mathrm{a}}$ & 5,57 \\
Músculo/osso & $4,26 \pm 0,1^{\mathrm{a}}$ & $3,53 \pm 0,2^{\mathrm{b}}$ & $3,50 \pm 0,1^{\mathrm{b}}$ & 7,14 \\
Porção comestível/osso & $5,53 \pm 0,2^{\mathrm{a}}$ & $4,90 \pm 0,2^{\mathrm{b}}$ & $4,87 \pm 0,2^{\mathrm{b}}$ & 7,04 \\
\hline
\end{tabular}

a,b letras minúsculas diferentes, na linha, diferem $(\mathrm{P}<0,05)$ entre si pelo teste ' $\mathrm{t}$ '.

Fonte: Elaboração dos autores. 
Os animais que não receberam suplementação na dieta apresentaram maior quantidade e percentagem de músculo, em comparação aos suplementados (Tabela 2), enquanto que à medida que se aumentou o nível de suplementação, a quantidade $(\mathrm{kg})$ de gordura na carcaça aumentou (Gordura, $\mathrm{kg}=36,98+$ $\left.8,87^{*} \mathrm{NS} ; \mathrm{P}=0,0799 ; \mathrm{R}^{2}=0,30\right)$. A literatura reporta o aumento na quantidade de gordura na carcaça com o aumento da densidade energética da dieta em animais em confinamento (GESUALDI JÚNIOR et al., 2000; RIBEIRO et al., 2001; MISSIO et al., 2010), porém, em pastagem, vários pesquisadores (RESTLE et al., 2001a; ZERVOUDAKIS et al., 2001; BASARAD et al., 2007) não observaram efeito da suplementação sobre a participação de gordura na carcaça.

Segundo Berg e Butterfield (1976), desde que o peso de abate seja semelhante, não são esperadas diferenças na composição corporal de bovinos. Em conseqüência da maior participação de músculo e menor de osso na carcaça dos animais não suplementados, estes apresentaram maiores relações músculo/osso e porção comestível/osso. A quantidade de músculos em relação à de ossos é uma característica importante, pois no momento da comercialização da carcaça desejam-se maiores quantidades de músculo e menores de ossos. Gesualdi Junior et al. (2000); Silveira et al. (2009); Missio et al. (2010) e Menezes et al. (2010) não observaram efeito do nível de concentrado sobre a relação músculo/osso. De acordo com Owens, Dubeski e Hanson (1993), o potencial genético dos bovinos é um fator mais preponderante na determinação da composição física da carcaça, que também foi confirmado por Menezes et al. (2005).

Entre os aspectos visuais da carne, apenas a textura foi influenciada pelos tratamentos, onde animais suplementados com $0,5 \%$ do peso vivo (PV) apresentaram textura mais fina em relação aos animais suplementados com 1,0\% do PV (Tabela 3).

Tabela 3. Médias, erros-padrão e coeficiente de variação (CV) para as características da carne de novilhos da raça Devon, mantidos em pastagem de milheto, de acordo com o nível de suplementação.

\begin{tabular}{llcll}
\hline & \multicolumn{3}{c}{ Níveis de concentrado, \% $^{*}$ CV, \% } \\
\cline { 2 - 4 } & \multicolumn{1}{c}{0,5} & 1,0 & 27,89 \\
\hline Cor, pontos $^{(1)}$ & $3,50 \pm 0,5$ & $2,67 \pm 0,5$ & $3,50 \pm 0,5$ & 9,34 \\
Textura, pontos $^{(2)}$ & $4,75 \pm 0,2^{\mathrm{ab}}$ & $5,00 \pm 0,3^{\mathrm{a}}$ & $4,25 \pm 0,2^{\mathrm{b}}$ & 48,02 \\
Marmoreio, pontos $^{(3)}$ & $5,50 \pm 1,4$ & $5,33 \pm 1,6$ & $6,75 \pm 1,4$ & 16,06 \\
Extrato etéreo, \% $_{\text {QDESC, \% }}$ & $2,25 \pm 0,2$ & $2,44 \pm 0,2$ & $2,39 \pm 0,2$ & 15,23 \\
QCO, \% & $12,5 \pm 0,9^{\mathrm{A}}$ & $9,8 \pm 1,0^{\mathrm{B}}$ & $10,8 \pm 0,9^{\mathrm{AB}}$ & 17,63 \\
Suculência, pontos $^{(4)}$ & $18,0 \pm 1,8^{\mathrm{b}}$ & $20,0 \pm 2,1^{\mathrm{ab}}$ & $24,1 \pm 1,9^{\mathrm{a}}$ & 9,19 \\
Palatabilidade, pontos $^{(4)}$ & $7,03 \pm 0,3^{\mathrm{a}}$ & $5,71 \pm 0,3^{\mathrm{b}}$ & $6,55 \pm 0,3^{\mathrm{ab}}$ & 5,69 \\
Shear, kgf/cm $^{3}$ & $6,56 \pm 0,2^{\mathrm{ab}}$ & $6,25 \pm 0,2^{\mathrm{b}}$ & $6,89 \pm 0,2^{\mathrm{a}}$ & 24,71 \\
Maciez, pontos $^{(4)}$ & $2,05 \pm 0,3^{\mathrm{b}}$ & $3,14 \pm 0,4^{\mathrm{ab}}$ & $3,37 \pm 0,3^{\mathrm{a}}$ & 6,28 \\
\hline
\end{tabular}

a,b letras minúsculas diferentes, na linha, diferem $(\mathrm{P}<0,05)$ entre si pelo teste ' $\mathrm{t}$ '.

A,B letras maiúsculas diferentes, na linha, diferem $(P<0,10)$ entre si pelo teste ' $t$ '.

(1) Escala de 1 a 5 pontos, sendo $1=$ vermelho escuro e $5=$ vermelho brilhante.

(2) Escala de 1 a 5 pontos, sendo 1 = muito grosseira e $5=$ muito fina.

(3) Escala de 1 a 18 pontos, sendo $5=$ leve; $6=$ leve mais e $7=$ pequeno menos.

(4) Escala de 1 a 9 pontos, sendo 1 = extremamente dura, sem sabor ou seca, 5 = médio e 9 - extremamente macia, extremamente saborosa ou extremamente suculenta.

Fonte: Elaboração dos autores. 
Ao trabalharem com vacas de descarte em pastagem recebendo ou não suplementação, Vaz et al. (2002); Restle et al. (2001a) e Menezes et al. (2009), não constataram influencia da dieta sobre a textura da carne, assim como Vaz et al. (2005) e Silveira et al. (2009) ao trabalharem com novilhos confinados recebendo diferentes níveis de concentrado na dieta. Contudo, Missio et al. (2010) observaram crescimento linear na textura da carne com o aumento de concentrado na dieta, fato este que atribuíram à diminuição da idade de abate dos animais que receberam altos teores de concentrado.

Os animais que não receberam suplemento apresentaram carnes com maior perda de peso ao descongelamento em relação aos que receberam concentrado ao nível de $0,5 \%$ do PV. Na literatura não estão relatadas muitas variações nessa característica quanto à inclusão de concentrado na dieta (VAZ et al., 2002; 2005; MISSIO et al., 2010). Segundo Costa et al. (2002), há uma associação negativa entre perda por descongelamento e marmoreio (aumentos no grau de marmorização da carne reduzem as perdas por descongelamento) e uma relação positiva entre marmoreio e perda por cocção (aumentos no grau de marmorização representam acréscimos nas perdas por cocção). No presente estudo não foi verificado relações entre marmoreio e perda de líquidos ao descongelamento, no entanto, embora semelhantes, os teores de marmoreio apresentaram comportamento linear crescente com as perdas à cocção, que segundo a equação de regressão, foi de $\mathrm{QCOZ}=17,71+6,08 * \mathrm{NS}\left(\mathrm{R}^{2}=0,40 ; \mathrm{P}=0,0359\right) . \mathrm{A}$ gordura de marmoreio é a última a ser depositada na carcaça, e é afetada pelo nível energético da dieta e também pelo peso do animal (COSTA et al., 2002; ARBOITTE et al., 2004). Os teores de extrato etéreo também não diferiram $(\mathrm{P}>0,05)$ quanto ao uso de suplementação energética.

Em relação às características organolépticas da carne, houve efeito dos tratamentos na suculência, palatabilidade e na força de cisalhamento $\left(\mathrm{kgf} / \mathrm{cm}^{3}\right.$ de fibra muscular). A carne proveniente de animais suplementados com $0,5 \%$ do PV apresentou menor suculência do que a carne daqueles não suplementados, e menos palatável do que aqueles que receberam suplementação energética ao nível de $1,0 \%$ do peso corporal. e palatabilidade em relação aos animais não suplementados e suplementados com $1,0 \%$ do $\mathrm{PV}$, respectivamente.

Segundo a análise de regressão, a força de cisalhamento (Shear) apresentou crescimento linear com o aumento no nível de suplementação $\left(\right.$ SHEAR $\left.=2,17+1,32 * N S ; R^{2}=0,44 ; \mathrm{P}=0,0247\right)$. Crouse, Calkins e Seideman (1986) afirmaram que diferenças de maciez da carne podem ser esperadas, quando animais possuem diferença no ganho de peso durante a terminação, pois o rápido crescimento muscular propicia a formação de colágeno de maior solubilidade. Nesse caso, tendo em vista que não houve diferença no GMD, a diferença na força de cisalhamento não pode ser atribuído a esse fator. Vaz et al. (2005) e Silveira et al. (2009), trabalhando em confinamento, e Menezes et al. (2009), em pastagem cultivada de inverno, observaram melhoria na maciez da carne com o aumento no nível de concentrado na dieta. Porém, estudos conduzidos por Vaz et al. (2002) e Missio et al. (2010), não demonstraram essa variação. Por sua vez, Menezes et al. (2010) ao avaliarem a terminação de animais em pastagem tropical,confinamento e pastagem de inverno, observaram que o tipo de volumoso pode interferir na maciez da carne, sendo esta menor em animais terminados em pastagem de inverno. Isso pode estar relacionado aos relatos de Vaz et al. (2007), que presumiram que animais mantidos em pastagem apresentam maior conteúdo de colágeno, tornando a carne mais dura. Por outro lado, Di Marco (1998) associaram a maciez da carne à maior deposição de gordura intramuscular e, portanto, à maior facilidade de rompimento dos sarcômeros e das fibras da carne. 


\section{Conclusões}

$\mathrm{O}$ aumento de suplementação com concentrado ao nível de $1,0 \%$ do peso vivo proporciona carcaças de melhor qualidade (maior rendimento, maior grau de acabamento, menor perda ao resfriamento, e melhor conformação) do que os não suplementados. Animais não suplementados apresentam carcaças mais compridas, com menor percentual de dianteiro, e maior relação músculo/osso do que os suplementados. Animais suplementados com concentrado ao nível de $0,5 \%$ do peso corporal apresentam carne com menor qualidade organoléptica.

\section{Referências}

ARBOITTE, M. Z.; RESTLE, J.; ALVES FILHO, D. C.; BRONDANI, I. L.; PACHECO, P. S.; MENEZES, L. F. G de; PEROTTONI, J. Composição física da carcaça, qualidade da carne e conteúdo de colesterol no músculo Longissimus dorsi de Novilhos 5/8 Nelore - 3/8 charolês terminados em confinamento e abatidos em diferentes estádios de maturidade1. Revista Brasileira de Zootecnia, Viçosa, v. 33, n. 4, p. 959-968, 2004.

BARONI, C. E. S.; LANA, R. P.; MANCIO, A. B.; QUEIROZ, A. C. de; LEÃO, M. I.; SVERZUT, C. B. Níveis de suplemento à base de fubá de milho para novilhos Nelore terminados a pasto na seca: desempenho, características de carcaça e avaliação do pasto. Revista Brasileira de Zootecnia, Viçosa, v. 39, n. 1, p. 175-182, 2010.

BASARAD, J. A.; MIR, P. S.; AALHUS, J. L.; SHAH, P. S.; BARON, V. S.; DUGAN, M.; OKINE, E. K.; ROBERTSON, W. M. Effect of sunflower seed supplementation on the fatty acid composition of muscle and adipose tissue of pasture-fed and feedlot finished beef. Canadian Journal of Animal Science, Ottawa, v. 87, n. 1, p. 71-86, 2007.

BERG, R. T.; BUTTERFIELD, R. M. New concepts of cattle growth. Sydney: Sydney University Press, 1976. $240 \mathrm{p}$.

COSTA, E. C.; RESTLE, J.; BRONDANI, I. L.; PEROTTONI, J.; FATURI, C.; MENEZES, L. F. C. de. Composição física da carcaça, qualidade da carne e conteúdo de colesterol do músculo Longissimus dorsi de novillhos Red Angus superprecoces, terminados em confinamento e abatidos com diferentes pesos. Revista Brasileira de Zootecnia, Viçosa, v. 31, n. 1, p. 417-428, 2002.
CROUSE, J. D.; CALKINS, C. R.; SEIDEMAN, S. C. The effects of rate of change in body weight on tissue development and meat quality of youthful bulls. Journal of Animal Science, Champaign, v. 63, n. 7, p. 1824-1829, 1986.

GESUALDI JUNIOR, A.; PAULINO, M. F.; VALADARES FILHO, S. C.; SILVA, J. F. C.; VELOSO, C. M.; CECON, P. R. Níveis de concentrado na dieta de novilhos F1 Limousin x Nelore: características de carcaça. Revista Brasileira de Zootecnia, Viçosa, v. 29, n. 5, p. 1467-1473, 2000.

HANKINS, O. G.; HOWE, P. E. Estimation of the composition of beef carcasses and cuts. Washington, D.C.: USDA, 1946. 21 p. (Technical Bulletin, USDA, n. 926).

JARDIM, P. O. C.; GUARENTI, N. M.; OSÓRIO, J. C. $\mathrm{S}$. Avaliação dos cortes dianteiro, costilhar e serrote em vacas de descarte. Pesquisa Agropecuária Brasileira, Brasília, v. 23, n. 5, p. 543-549, 1988.

MARSHALL, D. M. Breed differences and genetic parameters for body composition traits in beef cattle. Journal of Animal Science, Champaign, v. 72, n. 10, p. 2745-2755, 1994.

MENEZES, L. F. G.; RESTLE, J.; BRONDANI, I. L.; SILVEIRA, M. F. da; FREITAS, L. S.; PIZZUTI, L. A. D. Características da carcaça e da carne de novilhos superjovens da raça Devon terminados em diferentes sistemas de alimentação. Revista Brasileira de Zootecnia, Viçosa, v. 39, n. 3, p. 667-676, 2010.

MENEZES, L. F. G.; RESTLE, J.; VAZ, F. N.; BRONDANI, I. L.; ALVES FILHO, D. C.; FREITAS, A. K.; METZ, P. A. M. Composição física da carcaça e qualidade da carne de novilhos de gerações avançadas do cruzamento alternado entre as Raças Charolês e Nelore, terminados em confinamento. Revista Brasileira de Zootecnia, Viçosa, v. 34, n. 3, p. 946-956, 2005.

MENEZES, L. F. G.; SEGABINAZZI, L. R.; BRONDANI, I. L.; RESTLE, J.; ARBOITTE, M. Z.; KUSS, F.; PACHECO, P. S.; ROSA, J. R. P. Silagem de milho e grão de sorgo como suplementos para vacas de descarte terminadas em pastagem cultivada de estação fria. Arquivo Brasileiro de Medicina Veterinária e Zootecnia, Belo Horizonte, v. 61, n. 1, p. 182-189, 2009.

MISSIO, R. L.; BRONDANI, I. L.; ALVES FILHO, D. C.; RESTLE, J.; ARBOITTE, M. Z.; SEGABINAZZI, L. R. Características da carcaça e da carne de tourinhos terminados em confinamento, recebendo diferentes níveis de concentrado na dieta. Revista Brasileira de Zootecnia, Viçosa, v. 39, n. 7, p. 1610-1617, 2010. 
MOTT, G. O.; LUCAS, H. L. The design conduct and interpretation of grazing trials on cultivated and improved pastures. In: INTERNATIONAL GRASSLAND CONGRESS, 6., 1952. Proceedings... Pensylvania: State College Press, 1952. p. 1380-1395.

MÜLLER, L. Normas para avaliação de carcaças e concurso de carcaça de novilhos. 2. ed. Santa Maria: Imprensa Universitária, 1987. 31 p.

MÜLlER, L.; MAXON, W. E.; PALMER, A. Z. Evaluación de técnicas para determinar la composición de la canal. In: Memoria de la associación latinoamericana de producción animal. Guadalajara: ALPA, 1973. p. 75.

NATIONAL RESEARCH COUNCIL - NRC. Nutrient requirement of beef cattle. 7. ed. Washington, DC: NRC, 1996. 242 p.

OSMARI, M. P.; ARBOITTE, M. Z.; BRONDANI, I. L.; KUSS, F.; ALVES FILHO, D. C.; RESTLE, J. Vacas terminadas em campo nativo suplementadas com farelo de trigo ou farelo de arroz integral contendo ou não monensina sódica. Ciência e Agrotecnologia, Lavras, v. 32, n. 6, p. 1974-1980, 2008.

OWENS, F. N.; DUBESKI, P.; HANSON, C. F. Factors that alter the growth and development of ruminants. Journal of Animal Science, Champaign, v. 71, n. 11, p. 3138-3150, 1993.

RESTLE, J.; VAZ, F. N.; ROSO, C.; OLIVEIRA, A. N.; CERDOTES, L.; MENEZES, L. F. G. de. Desempenho e características de carcaça de vacas de diferentes grupos genéticos, submetidas a níveis de suplementação energética em pastagem cultivada de estação fria. Revista Brasileira de Zootecnia, Viçosa, v. 30, n. 6, p. 18131823, 2001b.

RESTLE, J.; PACHECO, P. S.; VAZ, F. N. Uso de animais zebuínos em cruzamentos de bovinos de corte no sul do Brasil. In: SIMPÓSIO BRASILEIRO SOBRE CRUZAMENTO DE BOVINOS DE CORTE, 1., 2003, Londrina. Anais... Londrina: IAPAR, 2003, v. 1, p. 1-35.

RESTLE, J.; VAZ, F. N.; ALVES FILHO, D. C.; PASCOAL, L. L.; OLIVEIRA, A. N. de; FATURI, C.; ARBOITTE, M. Z. Efeito da suplementação energética sobre a carcaça de vacas de diferentes idades, terminadas em pastagem cultivada de estação fria sob pastejo horário. Revista Brasileira de Zootecnia, Viçosa, v. 30, n. 3, p. 1076-1083, 2001a.

REZENDE, P. L. de P.; RESTLE, J.; FERNANDES, J. J. R. Carcass and meat characteristics of crossbred steers submitted to different nutritional strategies at growing and finishing phases. Ciência Rural, Santa Maria, v. 42, n. 5, p. 875-881, 2012.
RIBEIRO, T. R.; PEREIRA, J. C.; OLIVEIRA, M. V. M.; QUEIROZ, A. C.; CECON, P. R.; LEÃO, M. I.; COELHO, R.; MELO, A. Características da carcaça de bezerros holandeses para produção de vitelos recebendo dietas com diferentes níveis de concentrado 1. Revista Brasileira de Zootecnia, Viçosa, v. 30, n. 6, p. 21542162, 2001.

SANTOS, E. D. G.; PAULINO, M. F.; LANA, R. P.; VALADARES FILHO, A. de C.; QUEIROZ, D. S. Influência da suplementação com concentrados nas características de carcaça de bovinos F1 Limousin Nelore, não-castrados, durante a seca, em pastagens de Brachiaria decumbens. Revista Brasileira de Zootecnia, Viçosa, v. 31, n. 4, p. 1823-1832, 2002.

SAS INSTITUTE. SAS/STAT user's guide: statistics. 6. ed. Version 8. Cary, NC, 2002. v. 2, 943 p.

SILVA, F. F.; VALADARES FILHO, S. C.; ÍTAVO, L. C. V.; VELOSO, C. M.; PAULINO, M. F.; VALADARES, R. F. D.; CECON, P. R.; SILVA, P. P.; GALVÃO, R. M. Consumo, desempenho, características de carcaça e biometria do trato gastrintestinal e dos órgãos internos de novilhos nelore recebendo dietas com diferentes níveis de concentrado e proteína. Revista Brasileira de Zootecnia, Viçosa, v. 31, n. 4, p. 1849-1864, 2002.

SILVEIRA, M. F.; BRONDANI, I. L.; ARBOITTE, M. Z.; ALVEZ FILHO, D. C.; RESTLE, J.; PIZZUTI, L. A. D.; LUZ, T. R. R.; RETORE, M. Composição física da carcaça e qualidade da carne de novilhos Charolês e Nelore que receberam diferentes proporções de concentrado na dieta. Arquivos Brasileiros de Medicina Veterinária e Zootecnia, Belo Horizonte, v. 61, n. 2, p. 467-474, 2009.

VAZ, F. N.; RESTLE, J.; PADUA, J. T.; METZ, P. A. M.; MOLETTA, J. L.; FERNANDES, J. J. de R.; Qualidade da carcaça e da carne de novilhos abatidos com pesos similares, terminados em diferentes sistemas de alimentação. Ciência Animal Brasileira, Goiânia, v. 8, n. 1, p. 31-40, 2007.

VAZ, F. N.; RESTLE, J.; BRONDANI, I. L.; COSTA, E. C. da; VAZ, R. Z.; ROSO, C.; CARILHO, C. de O. Suplementação energética sobre a qualidade da carcaça e da carne de vacas de diferentes idades, terminadas em pastagem cultivada de estação fria sob pastejo horário. Revista Brasileira de Zootecnia, Viçosa, v. 31, n. 1, p. 173-182, 2002.

VAZ, F. N.; RESTLE, J.; SILVA, N. L. Q.; ALVES FILHO, D. C.; PASCOAL, L L.; BRONDANI, I. L.; KUSS, F. Nível de concentrado, variedade da silagem de sorgo e grupo genético sobre a qualidade da carcaça e da carne de novilhos confinados, concentrado, variedade da silagem de sorgo. Revista Brasileira de Zootecnia, Viçosa, v. 34, n. 1, p. 239-248, 2005. 
ZERVOUDAKIS, J. T.; PAULINO, M. F.; DETMANN, Desempenho e características de carcaça de novilhos E.; LANA, R. de P.; VALADARES FILHO, S. de C.; suplementados no período das águas. Revista Brasileira CECON, P. R.; QUEIROZ, D. S. de; MOREIRA, A. L. de Zootecnia, Viçosa, v. 30, n. 4, p. 1381-1389, 2001. 